\title{
Correction to: Systematic Review on Al-based Proctoring Systems: Past, Present and Future
}

\author{
Aditya Nigam ${ }^{1} \cdot$ Rhitvik Pasricha $^{1} \cdot$ Tarishi Singh $^{1} \cdot$ Prathamesh Churi $^{2}$
}

Published online: 15 December 2021

(c) Springer Science+Business Media, LLC, part of Springer Nature 2021

\section{Correction to: Education and Information Technologies (2021) 26:6421-6445 https://doi.org/10.1007/s10639-021-10597-x}

Some of the text in the Conclusion section of our article was copied from the equivalent section of an article by (Coghlan et al., 2020). However, the facts presented in (Coghlan et al., 2020) concerning remote proctoring systems were based on exam integrity, the privacy of the user, Trust factor, Transparency, etc. (Which is more philosophical as well as technical factors).

In turn, the overall conclusion of both the articles states that the advantages of these Online Proctoring technologies with Artificial Intelligence based assessment/ judgment are enough for us to use them in their current state even with the inherent risks such as privacy and trust are involved.

This error could be attributed to our inexperience and the superior impression that the said paper had on our minds. There was no malicious intent at our end and we agree that it should not have occurred.

We sincerely apologize for the inappropriate overlap between the two publications and our lack of transparency about the similarities between these articles.

The original article can be found online at https://doi.org/10.1007/s10639-021-10597-x.

Prathamesh Churi

Prathamesh.churi@ieee.org; Prathamesh.churi@gmail.com

Aditya Nigam

adityanigam002@gmail.com

Rhitvik Pasricha

pasricharhitvik@gmail.com

Tarishi Singh

tarishi1109@gmail.com

1 Computer Engineering Department, Mukesh Patel School of Technology Management \& Engineering, NMIMS University, Mumbai, India

2 Assistant Professor, Computer Engineering Department Mukesh Patel School of Technology Management \& Engineering, NMIMS University, Mumbai, India 


\section{References}

Coghlan, S., Miller, T., \& Paterson, J. (2020). Good proctor or "Big Brother"? AI Ethics and Online Exam Supervision Technologies. ArXiv Preprint ArXiv:2011.07647.

Publisher's Note Springer Nature remains neutral with regard to jurisdictional claims in published maps and institutional affiliations. 